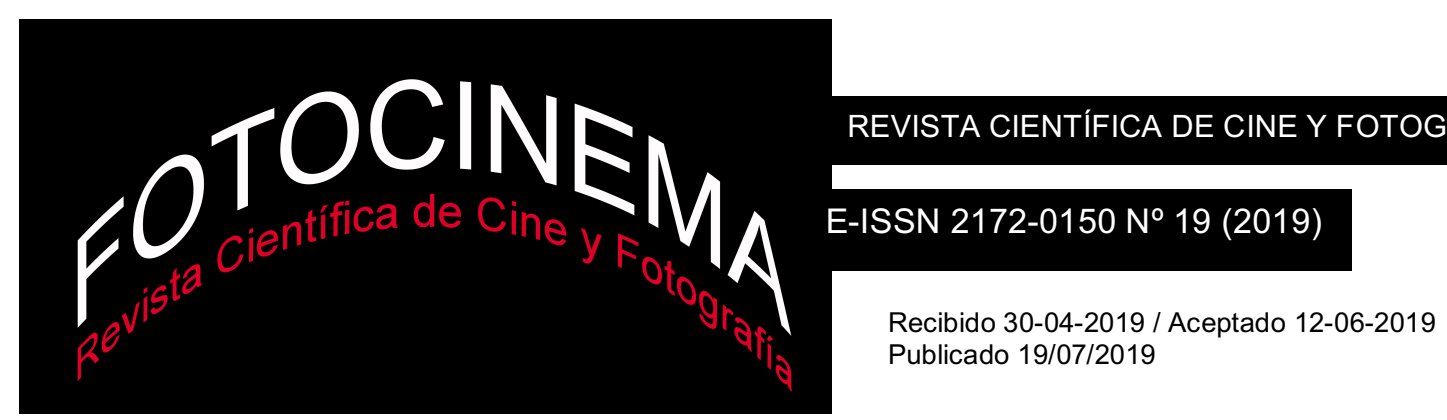

\title{
La mirada hipermétrope: el fotoperiodismo en la era de las redes sociales
}

\section{The hypermetrope view: photojournalism in the age of social networks}

\author{
Mar Marcos Molano \\ Universidad Complutense de Madrid, España \\ mmmarcos@ucm.es
}

Ana Tagarro

Universidad Complutense de Madrid, España atagarro@ucm.es

\section{Resumen:}

La difusión de fotografías vinculadas a la actualidad a través de las redes sociales antes incluso de ser publicadas en los medios de comunicación, ha alterado el rol tradicional de fotógrafos y de editores gráficos. Estas fotografías, vistas por millones de personas en todo el mundo y cuya difusión se produce a través de Twitter, Facebook o Instagram, eluden la fase de edición gráfica otrora fundamental en todo proceso de comunicación periodística, pues es en esta fase donde se otorga un sentido concreto y consciente a las imágenes. Esto supone que las fotografías son publicadas sin atender a ninguna estrategia de planificación ni revisión de la producción, lo que deriva en un uso descontrolado de la imagen periodística. Pero no solo ha sido eliminado el criterio de selección con la desaparición del editor gráfico, también la autoría, con fotógrafos fagocitados por los propios sujetos retratados, en imágenes donde no hay firma ni copyright, y donde la mirada del autor parece haber sido desplazada del visor de su cámara.

\begin{abstract}
:
The diffusion of photographs linked to current events through social networks, even before being published in the media, has altered the traditional role of photographers and graphic editors. These photographs, seen by millions of people all over the world and disseminated via Twitter, Facebook or Instagram, avoid the graphic editing phase that was once fundamental in any process of journalistic communication, as it is in this phase that images are given concrete and conscious meaning. This means that the photographs are published without any planning strategy or revision of the production, which leads to an uncontrolled use of the journalistic image. But not only has the selection criteria been eliminated with the disappearance of the graphic editor, but also the authorship, with photographers gobbled up by the subjects themselves portrayed, in images where there is no signature or copyright, and where the author's gaze seems to have been displaced from the viewfinder of his camera.
\end{abstract}

\section{Palabras clave:}

Redes sociales; fotografía de actualidad; fotoperiodismo; edición gráfica; autoría.

\section{Keywords:}

Social networks; Contemporary photography; Photojournalism; Graphic edition; Authorship. 


\section{Introducción}

En la última década, las nuevas tecnologías de la información han alterado de forma sustancial la forma en que la fotografía documental es tomada, procesada, difundida y percibida. El fotoperiodismo se enfrenta al escepticismo de la veracidad de sus imágenes, a la hipervisibilización de los acontecimientos en virtud de la opulencia de estas imágenes y a la necesidad de abarcar toda la realidad para descubrírsela al otro. Sin embargo, y dado el impacto que generan las fotografías documentales distribuidas a través de las redes sociales, resulta pertinente preguntarse si el final de la función testimonial de la fotografía que los teóricos de la postfotografía diagnosticaban, es una realidad o una falsa profecía derivada de la velocidad con la que los cambios se están produciendo en el ámbito de la comunicación.

Es indiscutible que nuestra memoria de la historia reciente sigue vinculada a fotografías estáticas más que a ninguna otra forma de visualización: la fotografía sigue siendo capaz de detener el tiempo y eso es lo que la hace extraordinaria. Sin embargo, el carácter ontológico de la fotografía como recuerdo - "ha estado ahí"-, se diluye en la necesidad del "estoy aquí" en aras de compartir la experiencia. Es la justificación de un presente que se devalúa si la imagen no es subida a las redes con urgencia. Esta es la razón por la que "estas imágenes ya no operan con el pasado, pues éste deja de estar en juego cuanto más se aleja del instante que intentamos comunicar" (Tranche, 2018, p. 119). Pareciera que lo importante no es la fotografía, en la medida que el acto fotográfico se amplía ahora a la necesidad de reenviar el resultado de esa exploración del mundo, confirmando el hecho de compartir con los otros ese momento y ese lugar de manera inmediata, y advirtiendo en su demora un ejercicio de demérito del presente y, por tanto, de la imagen misma. Esto se asocia a un efecto en cascada de imágenes que, en su superabundancia, hipervisibilizan los acontecimientos. Ello es debido a que la factura fotográfica se simplifica en sus procesos de producción y posproducción y se agiliza en su fase de distribución, lo que permite aglutinar en un mismo gesto al productor, al distribuidor y al consumidor de imágenes: el fenómeno de democratización 
de la fotografía se asocia a la posibilidad de crearla, de revelarla y de revelársela al mundo.

Es difícil sobreponerse a esta sobredosis de fotografías producidas sin control y subidas a las redes sin filtro. Imágenes ausentes de cualquier disciplina fotoperiodística que dificulta su papel y función en el contexto de la información. Imágenes de un discurso fragmentado a las que el observador trata de dar coherencia precisamente porque las presupone un acercamiento directo, sin mediación, al mundo y a su conocimiento:

... [las imágenes] convierten el mundo real en inagotable, siempre idéntico y siempre renovado, introducen lo inteligible o la mirada allí donde reina la incoherencia o lo invisible (...). En cierto sentido, las imágenes sirven de consuelo ante la imposibilidad de aprehender el mundo (Castro, 2012, p. 49).

En este recorrido de acercamiento al mundo, poco importa quien firme el proceso por el cual se ofrece al observador la mirada sobre lo contingente, puesto que esta mirada ni es única ni es decisiva. Las fotografías resultantes son imágenes autoexplicativas en tanto que no funcionan como "index" de lo acontecido y son las propias imágenes las que constituyen, en sí mismas, las noticias. En el núcleo de este pensamiento vuelve a transitar la necesidad de recoger todo lo que nos rodea y hacerlo patente al otro "fusionar el instante real, que produce, con el digital, que reproduce” (Tranche, 2018, p. 144), de manera que el fotógrafo accidental toma el relevo del fotoperiodista tradicional, despojándose de toda mirada y recogiendo el mundo sin intervenirlo en fotografías de dudosa calidad desde el punto de vista del lenguaje fotoperiodístico.

En cualquier caso, la proliferación de dispositivos para capturar imágenes provoca que cualquier suceso sea ilustrado y no necesariamente narrado. La rapidez con la que las imágenes ocupan los muros de las redes hace que se despeguen "del discurso que las contextualizaba, incardinaba y sometía a un sistema de legibilidad e interpretación. De ahí que circulen y se viralicen libres de cualquier pretensión de someterlas a un enunciado” (Tranche, 2018, p. 20). 


\section{Marco teórico y metodología}

\subsection{La era post-fotográfica como contexto de investigación}

El desarrollo de las tecnologías digitales aplicadas a la imagen fotográfica dibujó hace algunas décadas un escenario bifurcado en torno a dos ejes que mantienen en la actualidad dos interesantes formas de acercarse a lo fotográfico: por un lado, desde su identidad ontológica y, por otro, desde su identidad histórica. En esta segunda línea se sitúan autores como Tagg, quien señala que la imagen fotográfica no puede entenderse como un objeto individual, sino como parte de un conjunto de imágenes, prácticas y tecnologías. La fotografía no puede hablar de y por sí misma, dado que sus significados dependen de su contexto:

La fotografía como tal carece de identidad. Su situación como tecnología varía según qué relaciones de poder la impregnan. Su naturaleza como práctica depende de las instituciones y de los agentes que la definen y utilizan. Sus funciones como modo de producción cultural están ligadas a unas condiciones de existencia definidas, y sus productos son significativos y legibles solamente dentro de difusiones específicas. Su historia no tiene unidad. Es un paseo por un campo de espacios institucionales. Lo que debemos estudiar es ese campo, no la fotografía como tal (Tagg en Batchen, 2004, p. 12).

En la otra línea, de carácter ontológico, el pensamiento formalista de Szarkowski identificaba cinco rudimentos en la fotografía: el objeto mismo, el detalle, el encuadre, el tiempo y el punto de vista, siendo posible considerar la historia de la fotografía desde la paulatina concienciación del fotógrafo respecto a las características específicas del propio medio. Añade, no obstante, que el nacimiento de la fotografía surgiría de una "compleja ecología de ideas y circunstancias que engloba el ambiente intelectual, el clima político, la situación de la capación técnica y la sofisticación de la simiente”. (Szarkowski en Batchen, 2004, p. 21)

Sin embargo, estos planteamientos pueden alinearse en un diseño común, en tanto que los formalistas, "se ven de pronto construyendo los cimientos de dicha esencia sobre la base de la historia, [...en tanto que] los posmodernos, se encuentran de pronto intentando identificar epistemologías y estéticas 
fotográficas que son fundamentales, esenciales e intrínsecas” (Batchen, 2004, p. 27). Es en esta propuesta común donde instalamos nuestra investigación, interviniendo tanto en los procesos de producción de las obras fotográficas, como en sus contextos de recepción:

Las destrezas artesanales se han transformado en la pequeña caja de plástico gris del ordenador personal. En este nivel, se expresan el temor por la posible desaparición de las habilidades, las funciones sociales y las responsabilidades políticas asociadas a la vocación o la profesión de fotógrafo (...) Y para el consumidor de imágenes fotográficas, seguramente una parte importante de la población mundial a diferentes niveles ya no es posible mantener la creencia en un vínculo significativo entre la apariencia del mundo y la configuración concreta de una imagen material (Lister, 1997, p.16).

El discurso de la imagen digital obliga al receptor a una mayor cautela ante lo que hasta ahora era el mundo real captado por la cámara analógica. En este contexto, la imagen fotográfica ya no sirve para representar el acontecimiento sino más bien para revelar el acontecimiento a los demás. Se observa cómo las necesidades planteadas a las nuevas tecnologías en términos de realidad se traducen en procesos de desrealización: si la fotografía analógica construye una realidad dentro de un encuadre que no es sino el resultado de un encuentro con el mundo visible, la imagen digital crea otra realidad, la de la pura imagen.

En cualquier caso, lo fotográfico sigue presente aun cuando sus expresiones originales se hayan "desplazado" (en términos de Foucault), no sólo en virtud de unas nuevas tecnologías sino de una específica organización del conocimiento, la sociedad y la cultura. Lo que no implica dejar de insistir en la decisiva transformación de su significado y valor. La imagen fotográfica nacida en la era digital tiene que ser vista como un objeto cultural -y no solo tecnológico- que ensancha y enriquece nuestra percepción del mundo: "Sólo han evolucionado las herramientas (...). Si lo que nos interesa es el contenido, no tenemos nada que reprochar a este razonamiento. Otra cosa sería cuestionar si la fotografía digital es todavía fotografía” (Fontcuberta, 1992, pp. 146-147). 


\subsection{Representación, identidad e imaginarios, como método}

En este contexto de lo post-fotográfico, la metodología utilizada en la investigación permitirá reflexionar el contenido de lo fotográfico en su interacción con las redes de comunicación a través de un estudio de caso, la fotografía tomada a Mark Zuckerberg, fundador y consejero delegado de Facebook, en el Mobile World Congress (Barcelona, 21 de febrero de 2016) durante una demostración de tecnología de realidad virtual, difundida a través de Facebook por el propio Zuckerberg. La imagen se convirtió en objeto de debate y de un análisis metafotográfico en el que subyace la obsesión del poder -no necesariamente político- por el control de la imagen. El método de análisis elude los valores estéticos de la foto propiamente, en pro del análisis de coordenadas como la representación, la identidad y los imaginarios. La representación, entendida como las diferentes formas a través de las cuales las comunidades, de acuerdo con sus diferencias sociales y culturales, perciben y comprenden su sociedad; el imaginario, entendido como la creación de elaboraciones simbólicas de lo que no conocemos: "el imaginario invita a dejar de percibir la realidad como un espejo de las condiciones objetivas de los sujetos, es precisamente la falta de objetividad la que provoca que se exalte la imaginación de lo propio y la mediocridad de lo ajeno" (Milán, 2016, p.9); y la identidad, entendida como la exaltación de lo propio y estrategia que puede utilizarse a nivel individual: "el que está dispuesto a hacerse un retrato de sí mismo, sabe que tendrá que diferenciarse de los demás no sólo en los aspectos físicos que resultan los más evidentes y por lo tanto, los menos consistentes" (Milán, 2016, p.8).

Dado que la imagen no informa de manera objetiva, se convierte en un medio extraordinario utilizado por las élites políticas y económicas para construir imaginarios colectivos, al tiempo que deviene en testimonio que contiene mensajes particulares. Se hace entonces necesario aplicar una herramienta metodológica que nos permita una interpretación completa de la imagen y que hemos planteado en tres fases: la primera, consigna e identifica objetos, situaciones y personajes, significación primaria ubicada en el mundo fáctico; la segunda reconoce el tema y su significado convencional desde la 
descripción; la tercera explica la significación del contenido, ubicándose en el espacio de la interpretación.

\section{Fotografías y redes sociales: Zuckerberg, un caso de hipermetropía fotográfica}

El 21 de febrero de 2016, Mark Zuckerberg colgó en su página de Facebook -la red social de la que es creador y consejero delegado-, tres fotografías del Mobile World Congress de Barcelona en el que acababa de participar. Una de esas imágenes (F1) se viralizó rápidamente suscitando dieciséis mil comentarios en su página ese mismo día, y reproduciéndose en centenares de medios de comunicación de todo el mundo al día siguiente. La fotografía en si misma resultaba perturbadora: un hombre perfectamente reconocible, pasa entre muchos otros hombres conectados a sus ordenadores, cegados por unas gafas-máscara que les impiden ver la realidad que les rodea: ellos, con expresión seria o confundida; el hombre que pasa junto a ellos, sin embargo, sonríe. La fotografía era fácilmente identificable como una distopía que remitía a imágenes de referencia de la ciencia ficción.

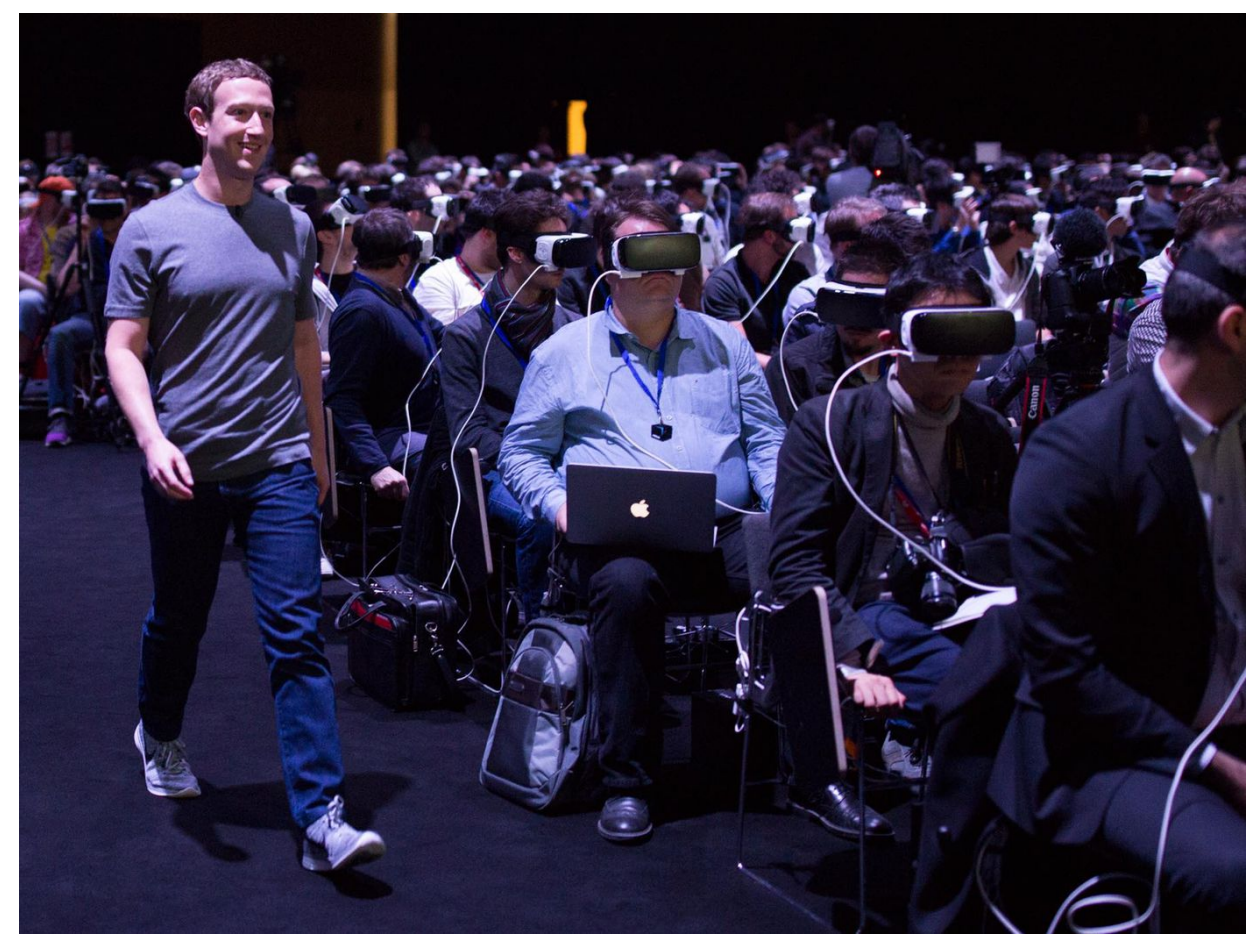

F1. Zuckerberg en el World Mobile Congres, @facebook/Zuckerberg, 2016 
La foto fue tomada en un momento en que el nombre de Facebook ya aparecía vinculado a la manipulación informativa, a las fakenews y al reciente triunfo de Donald Trump en las elecciones a la presidencia de Estados Unidos, pero bastante antes de que se supiese que Facebook había permitido la filtración de datos personales de sus usuarios a una empresa consultora que trabajaba para Trump con intención de influir ilegítimamente en su intención de voto. Sin embargo, 2016 marcó un punto de inflexión en la vida de Zuckerberg y, en consecuencia, en la forma en la que se mostraba en los medios: a Zuckerberg le conocemos desde 2004, cuando creó su mundialmente célebre e influyente red social, pero es en 2016 cuando empieza a elaborar la imagen (hipermétrope) de sí mismo, enfocando su mirada más allá del acontecimiento ante la desconfianza de lo contingente.

\subsection{Representación: la foto-noticia como metafotografía}

La fotografía no puede ser analizada solo como imagen periodística, sino como 'metafotografía', por lo que transmite de un momento puntual en la historia de la fotografía. En primer lugar, y respecto a su autoría, la fotografía carece de autor, apareció acreditada como “@facebook/Zuckerberg” pero es indiscutible que la foto no la tomó el sujeto que en ella está representado. La imagen fue tomada por un miembro de su equipo, aunque su nombre nunca se ha hecho público. De hecho, no podía ser de otra forma, porque solo él y unos pocos organizadores sabían cómo sería la entrada de Zuckerberg en el recinto. Ese día se presentaban las gafas Samsung Gear VR, que para recrear realidad virtual usan una tecnología desarrollada por Oculus Rift, una empresa comprada por Facebook en 2014. Con cierta frecuencia se pedía a los asistentes que se pusieran las gafas para ver presentaciones en $3 \mathrm{D}$ de productos de la compañía. En una de esas ocasiones, cuando les dijeron que se las quitasen, apareció Mark Zuckerberg sobre el escenario, mientras unos segundos antes había pasado junto a ellos sin que fuesen conscientes. No era más que una estrategia de marketing para impresionar a expertos y periodistas. En el evento había decenas de fotógrafos pendientes del escenario, donde ya se preveía que iba a haber una presentación relevante, pero ninguno de ellos captó la entrada de Zuckeberg porque desconocían que iba a tener lugar y, 
menos aún, el lugar por donde se produciría. Así pues, la imagen solo estaba a disposición del equipo de Mark Zuckerberg. Y si efectivamente un fotógrafo realizó la fotografía, fue el propio Zuckerberg quien la difundió, no considerando necesario acreditarla. La omisión de crédito es habitual en Zuckerberg, quien no considera necesario que las fotografías que cuelga en sus redes sociales aparezcan acreditadas, aunque sean hechas, como ocurre habitualmente, por profesionales a su servicio.

Desde 2016, un total de doce personas se ocupan de actualizar y gestionar los perfiles personales de Zuckerberg en redes sociales (Heath, 2017) entre ellas, varios fotógrafos, aunque solo el nombre de uno de ellos se conoce: Charles Ommanney, a quien contrató en 2017 para inmortalizar su recorrido por Estados Unidos con el fin de conocer mejor a sus habitantes. No es extraño que cargos como Zuckerberg tengan empleados que se ocupen de sus perfiles digitales: filtran comentarios y spam, escriben post, gestionan las fotos..., lo extraordinario es la cantidad de profesionales que se encargan de mantener este estado de hipermetropía fotográfica.

\subsection{Imaginario: la foto-noticia como transformación simbólica}

La decisión de subir la fotografía a su perfil se entiende fue tomada por Zuckerberg o, al menos, que la aprobara. Lo que parecía difícil de entender es que creyese que la foto le beneficiaba, aunque a ojos de un entusiasta de la realidad virtual, tampoco resulta difícil de explicar. También es posible que él o su equipo fuesen conscientes, previamente, del ruido que la imagen iba a generar. Pero dado el escaso tiempo entre el suceso y la difusión de la imagen en la red, no parece probable. Los primeros en criticar la imagen fueron los medios especializados en tecnología: "Lo más aterrador es que el propio Mark Zuckerberg eligiera compartir esa imagen de sí mismo, pensando que es una buena imagen (...). Zuckerberg quizá se hizo con la presentación de Samsung en la MWC, pero en esta imagen lamentable, como poco, se parece más a lo que él está planeando: robar nuestro cerebro" (McCormick, 2016). Los medios de comunicación tradicionales publicaron la foto ese mismo día en sus versiones digitales y, al siguiente, en las impresas. Pero no para ilustrar el evento, sino para analizar la foto en sí misma y la decisión de Zuckerberg de 
subirla a su perfil. Por su parte, la explicación del propio Zuckerberg argumentaba que lo que se había interpretado sobre la foto era lo opuesto a lo que estaba pasando:

Lo que estaba ocurriendo dentro de los headsets era un vídeo de niños jugando al fútbol en algún lugar lejano. Podías mirar alrededor y ver a los niños jugando al fútbol y era una experiencia compartida con todos los demás en ese lugar, algo que habría sido imposible experimentar de otra manera. (...) Creo que la gente tiende a preocuparse por cualquier nueva tecnología que aparece. Los críticos se preocupan por si pasamos tiempo prestando atención a ese nuevo tipo de medio o tecnología en lugar de hablar entre nosotros, porque eso sería de alguna forma aislante. Pero los humanos son fundamentalmente sociales. Así que creo que, en realidad, si una tecnología no nos ayuda a entendernos socialmente entre nosotros no va a enganchar y no va a tener éxito. Seguro que puedes retroceder a los primeros libros. Apuesto a que la gente decía: '¿por qué deberías leer cuando puedes hablar con otra gente?' La cuestión es que leer es lo que te permite tener una profunda inmersión en la perspectiva de otra persona. Lo mismo con los periódicos o los teléfonos o la televisión. Apuesto a que pronto ocurrirá con la realidad virtual” (Döpfner, 2016, entrevista).

La transformación simbólica que el propio Zuckerberg hace de la fotografía, se enfrenta al impacto de la lectura inicial que la fotografía causa pues, en los términos próximos, la imagen no transmite ese hermanamiento a través de una experiencia común y menos que esa experiencia fuese satisfactoria. De hecho, las personas que llevan las gafas están serias y parecen desorientadas. El único que sonríe es el que no lleva las gafas, que además camina con determinación. Es cierto que la interpretación de la fotografía depende de factores externos a la propia imagen, del contexto y la información previa que tengamos, pero en este caso la composición es lo suficientemente elocuente y definitoria. Incluso si no supiésemos quiénes son los retratados ni dónde se tomó la imagen, la superioridad del individuo sin gafas sobre el resto es una evidencia. La interpretación de la fotografía aparece como la metáfora del hipermétrope: Zuckerberg es capaz de ver con nitidez la realidad lejana que reproducen las gafas virtuales, en tanto que incapaz de empatizar con los sujetos que forman parte de su espacio fáctico. 
En este punto es donde podemos reflexionar sobre la labor de la edición gráfica y su infravaloración con el advenimiento de las redes sociales a fin de establecer los contenidos simbólicos de las imágenes, que ofrezcan el encardinamiento necesario para el sujeto observador:

A diferencia de los escritores y editores de texto que no cuestionan las reglas gramaticales, la edición de fotografía a menudo es un terreno resbaloso. Pocos son los que coinciden sobre qué es lo que comunica una fotografía y menos los que pueden expresarlo en palabras. (...) Hay muy pocos cursos en el mundo que le enseñen a uno editar fotografías. Parece tan obvio que se cree que cualquiera puede hacerlo (Ritchin, 2010, p.113).

\subsection{Identidad: la foto-noticia desposeída de autoría}

No es menos reseñable que ni la revista alemana que entrevistó a Zuckerberg, ni los cientos de medios que se hicieron eco de la imagen, se interesasen por quién era el autor de la foto o trataran de averiguarlo: "un miembro del equipo de Zuckerberg” pareció explicación suficiente. En 2013, el 80\% de las fotos publicadas en los periódicos europeos aparecían sin firma del fotógrafo.

Si los representantes de las vanguardias artísticas propusieron que el valor artístico no radicaba en la fabricación material de la obra, sino en el proceso mental de selección y decisión, la singularidad que añade la llamada era postfotográfica es expandir ese concepto más allá del arte e imbricarlo con la información. Se está produciendo un progresivo cuestionamiento de la noción de autor al tiempo que se legitiman las prácticas de adopción, los denominados “apropiacionistas", que reivindican como autor a aquel que edita la foto, la visibiliza y la pone en circulación en un determinado contexto.

En el caso que nos ocupa, al tratarse del perfil de Facebook de un hombre poderoso, él mismo se convierte en autor de la fotografía, en cuanto que le agrega voluntad de sentido. La artisticidad -en este caso la documentalidad-, no viene dada por la calidad de la manufactura artesanal o técnica, sino por su situación en un contexto particular de observación. Se entiende, por tanto, que esas fotos las publica el interesado con el objetivo de que tengan la mayor difusión posible. 
A esto se añade otro supuesto convertido en ley no escrita en tanto que el copyright de la imagen pertenece a quien la hace, no a quien sale en ella. Cuando el que hace la fotografía no aparece, el concepto mismo de copyright aparece despojado de su sentido:

La era de la Web 2.0 con su dinámica interconectada, es a la vez una amenaza y una promesa para la idea de que unas 'voces' fotográficas individualizadas marquen eficazmente las pautas básicas sobre el concepto de 'fotografía'. En un entorno de la imagen en que las fotografías se conectan y se comportan sin necesariamente adherirse a la soberanía de la autoría, la idea del fotógrafo se convierte en un concepto mermado y disperso y quizá también histórico (Cotton, 2015, p. 103).

De la importancia de la imagen es plenamente consciente Facebook desde su origen, no en vano la red nació en la universidad de Harvard para colgar fotografías de chicas y valorarlas según su grado de atractivo. Pero más relevante es el hecho de que cuando la compañía alcanzó su mayor crecimiento, entre los años 2010 y 2011, fue gracias a un equipo llamado Growth Team, ingenieros y psicólogos encargados de lo que llamaron "L6/7", esto es, conseguir que los usuarios se conectasen seis de siete días a la semana. Se trataba de usar cualquier mecanismo para que aumentase el engagement con la red. Una de las estrategias más eficaces que los ingenieros descubrieron, es que la gente encuentra prácticamente imposible no conectarse, tras recibir un email diciendo que alguien ha subido una foto de ellos mismos.

\section{Conclusiones}

La falta de procesos de higiene informativa en ausencia de la edición gráfica, nos sitúa frente a imágenes despojadas de discursos narrativos que anclen sus significados. Las imágenes contienen un mensaje propio, ajeno a las aseveraciones narrativas tradicionales, mientras parecen dejar de tener que ver con los procesos informativos, concretamente con sus autores, con los actores que retrata, con la relación que establece con los lugares o con los objetos, con los editores..., en su lugar emergen estrategias de difusión 
descontrolada, en la necesidad de compartir la imagen en un presente endeble que, pese a ello, parece ser lo único que legitima su valor.

En este contexto, la digitalización ha permitido a la imagen fotoperiodística producir imágenes que no tienen referente causal en el mundo de los objetos y de los hechos, creando otra realidad que dialoga en las redes en el marco de la simulación virtual, perdiendo su estatus originario y convirtiéndose en pura información visual. Esto obliga al receptor a ser prudente ante lo que ocurre no ya en el mundo, sino en la propia imagen: resulta paradójico, como en la imagen analizada, que el observador sea ajeno a lo que verdaderamente ocurre en la propia fotografía, que los retratados no se sepan retratados y que el único sujeto consciente de la imagen, sea aquel que firme la fotografía ante la evidencia manifiesta de no haber sido tomada por él. Es el triunfo de lo hiperfotográfico: "puede pensarse en ella como una fotografía que no requiere ni la simultaneidad ni la proximidad del que ve y de lo que es visto, y que considera como su mundo cualquier cosa que exista, existió o que podría existir.” (Lister, 1997, p. 282).

Mark Zuckerberg intenta construir una imagen pública de sí mismo desde el convencimiento, como empresario, de que debe hacerlo, pero desde la más absoluta incomodidad como persona. Está al frente de una empresa que se define por su capacidad y habilidad para conectar a la gente; que se sustenta sobre la defensa de la total transparencia, sosteniendo esa declaración también en la difusión masiva de imágenes, la mayoría, fotografías de su persona. De ahí la justificación de que sea él mismo el que las difunda. De ahí que no pueda dejar de fotografiarse. Sin embargo, las imágenes que coloca en las redes adolecen de una visión hipermétrope, como la mayoría de las fotografías generadas en la era de las redes sociales: son fotografías que no se enfocan en el plano de la imagen sino detrás, en el plano de las redes. Consecuentemente, las fotografías aparecen borrosas, sin codificación simbólica, alcanzando su presumible nitidez en la interacción virtual de las redes sociales. 


\section{Referencias bibliográficas}

Batchen, G. (2004). Arder en deseos, la concepción de la fotografía. Barcelona: Gustavo Gili.

Cotton, Ch. (2015). Don't call me a Photograper. Madrid: Ivory Press

Fontcuberta, J. (1992). El beso de Judas. Fotografía y verdad. Barcelona: Gustavo Gili.

Lister, M. (1997). La imagen fotográfica en la cultura digital. Barcelona: Paidós.

Milan, J.A. (2016). La imagen como herramienta de análisis para la historia. Una propuesta metodológica. Revista electrónica multidisciplinaria de investigación y docencia, $n^{o} 10$.

Ritchin, F. (2010). Después de la fotografía. México D.F.: Ediciones Serieve.

Tranche, R. (2019). La máscara sobre la realidad. La información en la era digital. Madrid: Alianza.

\section{Referencias hemerográficas}

Mathias Döpfner, Die Welt, publicado por Axel Springer, 28 de febrero de 2016. https://www.welt.de/wirtschaft/webwelt/article152719987/DieAngst-vor-kuenstlicher-Intelligenz-ist-hysterisch.html

Alex Heath, Business Insider, website de noticias financieras, propiedad de Axel Springer, 18 de julio de 2017.

https://www.businessinsider.com/mark-zuckerbergs-photographercharles-ommanney-follows-facebook-ceos-everywhere-2017-7? IR=T

Rich McCormick, The Verge, website de noticias tecnológicas, propiedad de Vox Media, 22 de febrero de 2016. https://www.theverge.com/2016/2/22/11087890/mark-zuckerbergmwc-picture-future-samsung 